\title{
CONTINUOUS EPIDURAL ANAESTHESIA IN THE COMMUNITY HOSPITAL
}

\author{
David H. Adamson, M.B., CH.B., F.R.C.P.(c)
}

The ADVANTAGes of continuous epidural anaesthesia during labour and delivery have been well documented., ${ }^{1,2}$ These studies, however, have been carried out in large hospitals where anaesthetists and residents were available within the hospital. Many anaesthetists are reluctant to start such a service in hospitals where an anaesthetist is not normally present 24 hours each day.

This study analyzes 704 consecutive cases conducted by the author during a four-year period. It was designed to answer the following questions:

(1) Is continuous epidural anaesthesia safe when no anaesthetist (and often no physician ) is present in the building?

(2) Should the anaesthetist return for the delivery?

(3) What modifications in technique are required?

(4) What problems emerge in initiating such a service?

\section{Complications}

The following complications have occurred:

(1) Hypotension

(2) Faulty catheter placement

(3) Accidental spinal

(4) Exaggerated spread of the terminal dose

(5) Resistance to local anaesthetics

(6) Tachyphylaxis

(7) Intravascular injection

(8) Foetal depression or stillbirth

(9) Caesarean sections
Percentage

$$
\text { ToraL } \overline{74} \quad \overline{(10.5)}
$$

Only one complication has been life threatening to the mother. This patient became hypotensive after the initial injection of 6 ccs of 1.5 per cent lidocaine with adrenaline, but her blood pressure immediately returned to an acceptable level when she was placed on her side. When put on the delivery table in the head-

St. Thomas Elgin General Hospital, St. Thomas, Ontario, Canada. 
up position and given a $10 \mathrm{cc}(150 \mathrm{mgm})$ terminal dose she became very hypotensive (B.P. $<60 /$ ) and fainted. Fortunately, the obstetrician arrived and her legs were put in the lithotomy position, her head lowered and oxygen administered. She promptly recovered and the comfortable delivery of a healthy baby proceeded without further complication. When this happened I was in the hospital, but fully occupied giving a general anaesthetic on another floor. This case resulted in certain modifications to the techniques which are described below. The other ten cases of hypotension have been amenable to treatment. Two patients early in the series received $1 \mathrm{mg}$ and $2 \mathrm{mg}$ of aramine, respectively. Others have been treated by displacement of the uterus and intravenous fluids only.

The ten cases of faulty catheter placement other than those placed intraspinally included five in which the catheter was reinserted, three in which it was not because the patient delivered before re-insertion could be effected and two in which the patient was so obese that the original insertion was only speculative and in which no further attempt was made.

Accidental spinal puncture occurred on seven occasions. Four of these were consecutive cases. Investigation revealed that new sharp epidural needles had replaced the old blunt ones. In one case the spinal anaesthesia was not recognized until the second injection, when $6 \mathrm{ccs}$ of 1.5 per cent lidocaine (xylocaine) with adrenaline produced a profound block to T-2 level. The blood pressure was supported with intravenous fluids and labour continued normally. Thirty milligrams of plain lidocaine into the catheter ensured a comfortable delivery. Accidental spinal tap otherwise was treated by re-inserting the catheter in the same space or preferably the one above. Nurses did not give subsequent injections until it was quite definite that epidural and not spinal analgesia was being produced and plain lidocaine was substituted for lidocaine with adrenaline.

Exaggerated spread of the terminal dose occurred on two occasions when contractions were too close together to permit injection between contractions. Other than anaesthesia to T-2 and T-4, no ill effects occurred.

Four patients were encountered who required large doses of local anaesthetic agents (up to $270 \mathrm{mgms}$ lidocaine) to ensure relief. This caused no problem other than requiring longer to be spent initiating the anaesthesia as the initial dose had to be determined by titration.

Tachyphylaxis was the commonest complication. This was compounded in the early months by the obstetrician suggesting that the patient might progress more rapidly if the epidural was stopped and asking nurses not to give any more anaesthetic in the meantime. The block would then wear off. Education and insistence that orders pertaining to an epidural could only be given by an anaesthetist solved this problem.

The one case of intravascular injection occurred when some anaesthetic presumably leaked intravenously at the time of the terminal dose. The patient complained of headache and became hypertensive with tachycardia. Perineal relaxation was good and delivery was comfortable. The mother's symptoms regressed in one-half hour. Blood was found in the tip of the epidural catheter on its removal.

Nine babies with Apgar scores of six or less were delivered in the series. Depression in eight of these was not related to the epidural anaesthesia. Five were 
very small or had congenital abnormalities incompatible with life. Two who were depressed were under five pounds and had received narcotics prior to their epidural and about two hours before delivery. One stillbirth had no apparent cause of death, but the foetal heart had not been heard since admission to the hospital. One elderly primiparous patient with a breech presentation who failed to progress developed foetal distress and suffered a hypotensive episode while preparations were being made for caesarean section. A stillborn foetus was delivered. Only in this last case could the epidural anaesthetic come under any suspicion.

The caesarean section rate of 2.6 per cent compares with a hospital rate of 4.5 per cent. Although elective caesarean sections and those with placenta praevia did not have epidurals, most of those undergoing a trial of labour received this form of anaesthesia. It is obvious that the number of caesarean sections was not increased by this type of treatment.

The complications which have required the return of the anaesthetist to the hospital between starting the epidural and moving the patient to the delivery room thus number nine ( 1.3 per cent); (eight catheter misplacements and one accidental spinal). None have been life-threatening. From initiation until delivery seemed not to require the presence of a physician in the building as long as competent nursing care was present and careful technique was followed.

\section{Should the Anaesthetist Return for Delivery?}

This is a question to which no clear-cut answer emerged. It is obviously desirable to have an anaesthetist present to treat any complications which may arise and to resuscitate depressed babies, but it is also apparent that the anaesthetist will sometimes be fully occupied elsewhere. In the first 141 cases, I was present at the delivery on 113 occasions and not present on 28 . On four occasions when I was present ( 3.6 per cent) and four when I was not ( 14.3 per cent), hypotension developed. In the last 157 cases of the series no complications occurred in the 23 cases where I could not attend to the delivery. This reflects improved technique and the experience of the nursing staff in managing the patients under epidural analgesia. I have the impression that if no complications have occurred, the patient is comfortable, has had several injections, the foetal heart is good, the baby mature, and the obstetrician accustomed to delivering patients under epidural anaesthesia, then the attendance of the anaesthetist, although desirable, is not essential.

\section{TECHNIQUe}

The epidural catheter was inserted at L-2, 3 or L3, 4 using the loss of resistance test to identify the epidural space. ${ }^{3}$ If delivery was imminent, puncture was made at L-4, 5. An initial dose of $6 \mathrm{ml}$ of 1.5 per cent lidocaine with adrenaline was given and to ensure that the catheter had not pierced the dura, at least $2 \mathrm{ml}$ was given through the catheter. Originally, to ensure evenness of spread, the patients were nursed on their backs. To avoid the supine hypotensive syndrome, they were latterly nursed on either side, being turned 2 to 3 minutes after each injection. 
Patients were kept in a slight head-up position. The blood pressure was checked every five minutes for 20 minutes, then every 20 minutes and if the patient felt nauseated, weak or became sweaty. Nurses have been taught to give the intermittent injections between contractions.

Injections of $6 \mathrm{ml}$ of 1.5 per cent lidocaine with adrenaline (90 mgms) were given hourly p.r.n., unless tachyphylaxis developed or the excessive shaking (sometimes seen with lidocaine) occurred, when a change to carbocaine in the same dosage and strength was made. Provided this dosage was not exceeded and the patient was in a slightly head-up position, if an accidental spinal anaesthesic occurred, it was unlikely to spread above the T-2 level. Should intravascular injection have occurred, $90 \mathrm{mgm}$ lidocaine is in the range of dosage used for treatmeat of cardiac arrythmias and its cardiovascular action is reversed by the adrenaline. So, hopefully, no mishap would have occurred. That dose of lidocaine is also sufficiently small that it is in the anticonvulsive range. ${ }^{4}$

For the past two years all patients in labour have received intravenous fluids. usually 5 per cent $\mathrm{D} / \mathrm{W}$. The intravenous is started when the patient is in well established labour. Patients have been given $500 \mathrm{ml}$ of lactated Ringer's solution as fast as possible, whenever hypotension has developed. The terminal dose is now given with the head slightly elevated and only after the legs have been raised into the lithotomy position. Since this approach has been adopted, no patient has become hypotensive when placed on her back on the delivery-room table.

Epidural analgesia was not started until the cervix was $6 \mathrm{~cm}$ dilated in primiparous patients and 4 to $5 \mathrm{~cm}$ dilated in multiparous. This was an attempt to avoid protracted epidurals in which there was a greater chance of development of tachyphylaxis, with the risk that the patient would not receive relief when it was most needed.

\section{Problems Emerging on Setting up such a Service}

The problems which have emerged are those of education and manpower.

It was apparent in our setting that the success of this service was dependent on the co-operation of the nursing staff. Since only specially designated nurses could be permitted to make injections, some training programme was required. This took the form of a lecture or the showing of a film on the technique, followed by the author supervising the nurses while they cared for three such patients. The underlying principles and possible dangers were discussed with each nurse at that time, which also provided an opportunity to answer the nurses' questions. Once initial training had been completed it was reinforced at intervals by a lecture or further film show. How often this is required depends on the turnover of staff and the number of cases. Having had a fairly stable staff, one lecture every 9 to 12 months has been adequate.

Education of the medical staff was also required. Many were used to the baby being pushed out and to allowing posterior presentations to rotate. The change to almost routine forceps delivery and rotating posterior presentations had to be balanced in each physician's mind against the advantages of epidural anaesthesia. notably the comfort of the mother, the lack of foetal depression, and the ease with 
which the uterus could be explored postpartum. A few cases occurred where the patient would continue to labour, but stay at $6 \mathrm{~cm}$ dilatation. Some physicians had to be educated that the treatment of this, as long as the foetal head is low, is rupture of the membranes rather than stopping the epidural.

These problems, however, have been minor and no more than one expects when a new procedure is introduced. The rapid acceptance of the technique by patients, nurses and physicians has paralleled other centres and 75 per cent of our deliveries are now under epidural anaesthesia.

During the period of initial nurse training a very heavy load is placed on the supervising anaesthetists. After this period the load lightens, but each patient requires the anaesthetist to make two trips to the hospital or to stay longer at the hospital. For this reason there should be a sufficient number of anaesthetists involved, or willing to learn the technique so that nights "on call" do not come round too often.

\section{SUMMARY}

Continuous epidural anaesthesia appears to be a safe procedure in hospitals where no anaesthetist is present 24 hours per day, provided the technique adopted includes injection of part of the initial dose through the catheter, routine intravenous therapy, injection of the terminal dose after the patient's legs are raised into the lithotomy position; and provided that supervision of the patient is by specially trained nurses. It seems desirable, but not essential, that the anaesthetist return for delivery. To introduce this technique one must be prepared to educate the nurses and secure the co-operation of the physicians involved.

\section{RÉSUMÉ}

L’anesthésie épidurale continue semble être une méthode de toute sécurité dans les hôpitaux où un anesthésiste n'est pas présent 24 heures par jour, à la condition, toutefois, que la technique acceptée comprenne l'injection d'une partie de la dose initiale dans le cathéter, la thérapie par voie endoveineuse de routine, l'injection de la dose terminale après que les jambes de la malade soient levées en position de lithotomie; à la condition également que la surveillance de la malade soit faite par des infirmières spécialement préparées à ce travail. Il nous semble désirable, sans que la chose soit essentielle, que l'anesthésiste se rende pour l'accouchement. Pour établir la pratique de cette technique, l'anesthésiste doit consentir à former des infirmières et s'assurer la coopération des médecins concernés.

\section{ACKNowledgments}

I would like to thank W.G. Sloan, M.D., F.R.C.P.(C) for his assistance during this series, W.E. Spoerel, M.D., F.R.C.P.(C) and D.V. Catton, M.D., F.R.C.P.(C) for their encouragement to publish this paper and Miss Helen Wisener for typing the manuscript. 


\section{REFERENCES}

1. Kandel, P.F., Spoerel, W.E., \& Kinch, R.A.H. Contintous epidural analgesia for labour and delivery. Canad. Med. Assoc. J. 95: 947-953 ( 1966 ).

2. Catron, D.V. Epidural analgesia for labour and delivery. Anesth. \& Analg. 48: 587591 (1969).

3. Bromage, P.R. Spinal Epidural Analgesia. E. \& S. Livingstone, Edinburgh (1954).

4. Bohm, E., Flodmark, S., \& Petersen, I. Effect of lidocaine (xylocaine) on seizure and interseizure electroencephalograms in epileptics. A.M.A. Archs. Neurol. Psychiatry. 81: 550-556 (1959). 